\title{
Endotypes of chronic rhinosinusitis with nasal polyps with and without NSAID - intolerance*
}

\author{
Urs C. Steiner"\#, Sabrina Bischoff", Alan Valaperti' , Kristian Ikenberg33, \\ Joanna Starzyk², Sarina Bucher², Lucas M. Bachmann, Michael B. Soyka² \\ ' Department of Immunology, University Hospital Zurich, Zurich, Switzerland \\ ${ }^{2}$ Department of Otorhinolaryngology, Head and Neck Surgery, University Hospital and University of Zurich, Zurich, Switzerland \\ ${ }^{3}$ Department of Pathology and Molecular Pathology, University Hospital and University of Zurich, Zurich, Switzerland \\ ${ }^{4}$ Medignition - Healthcare Innovations, Zurich, Switzerland
}

Rhinology 58: 6, 544 - 549, 2020

https://doi.org/10.4193/Rhin 19.423

*Received for publication:

November 24, 2019

Accepted: April 30, 2020

"contributed equally

\begin{abstract}
Background: Chronic rhinosinusitis with nasal polyps (CRSwNP) is a type 2-dominated inflammatory disease of the upper airways. A subgroup of patients with CRSwNP suffer from intolerance to nonsteroidal anti-inflammatory drugs (NSAID) and develop NSAID-exacerbated respiratory disease (NERD). The aim of the study was to compare the cytokine based inflammatory endotype of nasal secretions of CRSwNP patients with and without NSAID intolerance.
\end{abstract}

Methods: Nasal secretions were collected from twenty-six patients suffering from CRSwNP, thirteen with NERD and thirteen without NSAID intolerance. As control, nasal secretions were collected from fifteen healthy donors. Tryptase and ten human cytokines were analyzed: interleukin (IL)-4, IL-5, IL-6, IL-8, IL-12p70, IL-13, IL-17A, IL-23, IFN- $\gamma$, and TNF- $\alpha$ by a cytokine multiple array on a Luminex 200 platform.

Results: Grade of polyposis and frequency of polyp surgery was more severe in NERD- compared to non-NERD patients. IL-6 and IL-5 in CRSwNP was significantly increased compared to healthy participants. IL-5 and IL-13 were significantly increased in subjects suffering from NERD compared to CRSwNP patients without NERD.

Conclusion: We identified IL-13 as a possible specific biomarker in nasal secretions of patients with NERD, which allows us to differentiate between CRSwNP with vs. without NERD. The characterization of inflammatory endotypes in CRSwNP enables the introduction of the best available therapy in the context of precision medicine.

Key words: chronic rhinosinusitis with nasal polyps, asthma, NERD, NSAID, inflammation

\section{Introduction}

Chronic rhinosinusitis (CRS) is characterized by inflammation of the nose and paranasal sinuses and affects about $12 \%$ of the population ${ }^{(1-3)}$. It is differentiated into the two major phenotypes: chronic rhinosinusitis without nasal polyps (CRSsNP) and chronic rhinosinusitis with nasal polyps (CRSwNP) ${ }^{(2,4)}$. CRSwNP affects approximately $1-4 \%$ of the general population. According the recent literature in CRSwNP a mixed T-helper (Th)-1/ Th2 inflammation can be identified ${ }^{(4,5)}$. However, most Caucasians affected by CRSwNP demonstrate an eosinophilic inflammation with mucosal infiltration of type $2 \mathrm{~T}$-cells, innate lymphoid cells (ILCs), eosinophils and mast cells. The cytokine milieu of CRSwNP typically includes interleukin (IL)-4, IL-5-and IL-13, eotaxin-1/2/3 and eosinophilic cationic protein (ECP) ${ }^{(6-8)}$. An important subtype of CRSwNP patients suffer from non-steroidal anti-inflammatory drug (NSAID) exacerbated respiratory disease (NERD) with the clinical symptoms of nasal polyposis and asthma. Approximately $9.7 \%$ among patients with nasal polyps, $8.7 \%$ among those with chronic sinusitis and $7.1 \%$ of asthma patients are suffering from NERD ${ }^{(9,10)}$. The pathogenesis of NERD is related to abnormalities of the cyclooxygenase - and lipoxygenase- derived arachidonic acid metabolism ${ }^{(11)}$. Chronic eosinophilic airway inflammation is more intense and recurren- 
ce of nasal polyps after surgery is more frequent in NERD than in NSAID - tolerant CRSwNP patients ${ }^{(10,12)}$. In both phenotypes, the histology of polyps shows an eosinophilic inflammation in the tissue but they often present with distinct clinical courses, therefore the underlying inflammatory endotype seems to be different. The aim of this study was to investigate and to compare the inflammatory endotype of CRSWNP patients with NERD and without NSAID intolerance using a non-invasive test to define nasal cytokine patterns.

\section{Materials and methods}

Ethics approval and consent to participate The local ethical Review Board of Zurich approved the study protocol (KEK2017-00810). The study strictly adhered to the principles of good clinical practice and the ethical standards outlined in the declaration of Helsinki ${ }^{(13)}$. All participants provided written informed consent.

\section{Patients}

Fifteen healthy volunteers were recruited from the clinic of otorhinolaryngology for non-CRS related problems. Twenty-six patients suffering from eosinophilic CRSwNP, proven by histology of preceding polyp operations, thirteen meeting the criteria for NERD by a clear medical history of respiratory symptoms 1-2 hours after ingestion of an NSAID, and thirteen CRSwNP patients without NSAID intolerance were recruited from either the department of otorhinolaryngology or clinical immunology after thorough examination by a senior consultant. Complete medical history according asthma was obtained from all participants and every individual underwent clinical examination including rhinoendoscopy. The extent of polyposis was judged according to the Davos scoring system for each side separately.

\section{Collection of nasal secretions}

Nasal secretions were collected from all participants in both nostrils separately. Neurosurgical patties (Neuray, Medtronic, Jacksonville, FL, USA) were introduced into the nostrils above the inferior turbinate on both sides and kept in situ for 10 minutes. Patties were then removed and weighed. Immediately after collection two-hundred microliters of diluent ( $\mathrm{NaCl} 0.9 \%)$ was added and the patties were centrifuged at $1000 \mathrm{rpm}$ for 5 minutes at room temperature. Secretions were collected, aliquoted and stored at $-80^{\circ} \mathrm{C}$ for analysis.

\section{Cytokine analysis}

Cytokines were analysed by a cytokine multiple array on a Luminex 200 platform (Luminex Corporation, Austin, TX, USA) with a high sensitive Milliplex kit (HSTCMAG-28SK-10) customized by Merk Millipore, containing the following ten human cytokines: IL-4, IL-5, IL-6, IL-8, IL-12p70, IL-13, IL-17A, IL-23, IFN- $\gamma$, and TNF- $\alpha$. This array includes cytokines that promote Th cell differentiation or cytokines produced by differentiated Th cell subpopulations. IL-12p70 and IFN- $\gamma$ are related to Th 1 cells, IL-4, IL-5, and IL-13 to Th2 cells, and IL-6, IL-17A and IL-23 to Th17 cells ${ }^{(14)}$. Monocytes/ macrophages and activated $T$ cells are the major producers of TNF- $\alpha{ }^{(15)}$, while IL-8, also called C-X-C Motif Chemokine Ligand $(C X C L) 8$, is released by a wide variety of immune and non-immune cells to predominantly mobilise neutrophils ${ }^{(16)}$. Cytokine measurement was always performed with a new aliquot. After thawing, aliquots were not frozen again for further analysis. Aliquots from both nostrils were analyzed and for each cytokine and the tryptase the average was calculated.

\section{Statistical methods}

We summarized continuous variables with means and standard deviations (and ranges), and dichotomous variables with percentages. Statistical testing was performed with parametric and non-parametric methods as needed. A p-value $<5 \%$ was considered statistically significant. In an exploratory approach, we dichotomized IL-13 mean values at $2.7 \mathrm{pg} / \mathrm{ml}$ and IL-5 mean values at $10 \mathrm{pg} / \mathrm{ml}$. This assessment allowed a clustering of subjects into four groups. In two univariate logistic regression models we assessed IL-13 and IL-5 mean values to predict wether NERD was present in CRSwNP patients. We plotted the area under the receiver operating characteristic curve (AUC) of IL-13 values as this parameter was significantly associated with the outcome. From the AUC, we identified the threshold with maximizing specificity at an optimal sensitivity. We calculated sensitivity and specificity along with binomially exact $95 \%$ confidence intervals. Statistical analyses were performed using the Stata 16.2 software package (StataCorp. 2019. Stata Statistical Software: Release 16. College Station, TX: StataCorp LP).

\section{Results}

\section{Clinical characteristics}

The analysis was based on 41 consenting participants. Fifteen controls (9 women, 6 men; mean age 34.4 years; SD 16.5; range 21-68); 13 affected by NERD ( 4 women, 9 men; mean age 47.4 years; SD 13.7; range 31-69) and 13 CRSwNP patients without NSAID intolerance (3 women, 10 men; mean age 54.2 years; SD 15.5; range 28-72). Patients affected by NERD suffered from a higher grade of polyposis (3.1 vs 2.1), suffered more often from asthma (100\% vs $31 \%)$, and experienced more sinus surgeries (2.2 vs 1.1) compared to the non-NERD patients. Intensity of therapy with topical Glucocorticosteroid (GCS) was comparable, while one patient with NERD was on systemic Prednisone $5 \mathrm{mg} / \mathrm{d}$ (Table 1).

Comparison of nasal cytokine pattern from healthy controls and patients with CRSwNP with and without NSAID intolerance

The cytokine pattern of nasal secretion was analyzed from 
Tabel 1. Characteristics of 26 CRSwNP patients with NERD (13) and without NSAID intolerance (13).

\begin{tabular}{|c|c|c|}
\hline parameter & NERD & no NSAID intolerance \\
\hline women/men & $4 / 9$ & $3 / 10$ \\
\hline $\begin{array}{l}\text { mean age } \\
\text { (years) }\end{array}$ & $\begin{array}{l}47.4 \text { (SD 13.7; } \\
\text { range 31-69) }\end{array}$ & $\begin{array}{l}54.2 \text { (SD 15.5; } \\
\text { range 28-72) }\end{array}$ \\
\hline $\begin{array}{l}\text { grade of polyposis } \\
\text { (mean) }\end{array}$ & 3.1 & 2.1 \\
\hline $\begin{array}{l}\text { polyp operations } \\
\text { (mean) }\end{array}$ & 2.2 & 1.1 \\
\hline GCS topic & 12 & 13 \\
\hline GCS systemic & 1 & 0 \\
\hline asthma & $13(100 \%)$ & $4(31 \%)$ \\
\hline
\end{tabular}

CRSwNP: Chronic rhinosinusitis with nasal polyposis; NERD: NSAID exacerbated respiratory disease; NSAID: non steroidal anti-inflammatory drugs; GCS: Glucocorticosteroids; Dose of systemic GCS: $5 \mathrm{mg}$ Prednisone/d; Dose of systemic GCS: $5 \mathrm{mg}$ Prednison/d.

fifteen healthy controls and twenty-six patients with CRSwNP of which thirteen were affected from NERD.

Compared to healthy participants, cytokines in nasal secretion of CRSwNP without NERD revealed a significant elevation of IL-6 and IL-5.

In addition NERD patients also showed significantly increased amounts of tryptase and IL-13 when compared to healthy controls.

The difference of the inflammatory endotype between CRSwNP with and without NSAID intolerance was the increased IL-5- and IL-13 values in NERD (Table 2). When setting the IL-13 cut-off value at $\geq 2.7 \mathrm{pg} / \mathrm{ml}$, presence of NERD was correctly detected in 10 out of 13 patients (sensitivity: $76.9 \%$ (95\% Cl: $46.2 \%$ to $95 \%$ )) and correctly detected in all 13 patients without NERD (specifity $100 \%$ (95\% Cl: $75.3 \%$ to $100 \%)$ ). The corresponding AUC was 0.861 (Cl: 0.702-1.000) indicating an excellent discrimination. Figure 1 shows the distribution of subjects within four clusters of IL-13 and IL-5 values. While all healthy subjects and all those presenting with polyps in absence of NERD grouped in the lower left quadrant, subjects with polyps and NERD showed a heterogeneous pattern but predominantly (10/13) had IL-13 values $\geq 2.7 \mathrm{pg} / \mathrm{ml}$.

\section{Discussion}

In this study we investigated the inflammatory endotype of CRSwNP with and without NSAID intolerance according the cytokine pattern of nasal secretion. We are in need for adequate biomarkers of these patients in order to characterize the different inflammatory endotypes and to establish targeted treatments ${ }^{(17)}$. The epithelium in CRSwNP is leaky due to malfunctioning tight junctions ${ }^{(18)}$. Thus we suspect that nasal

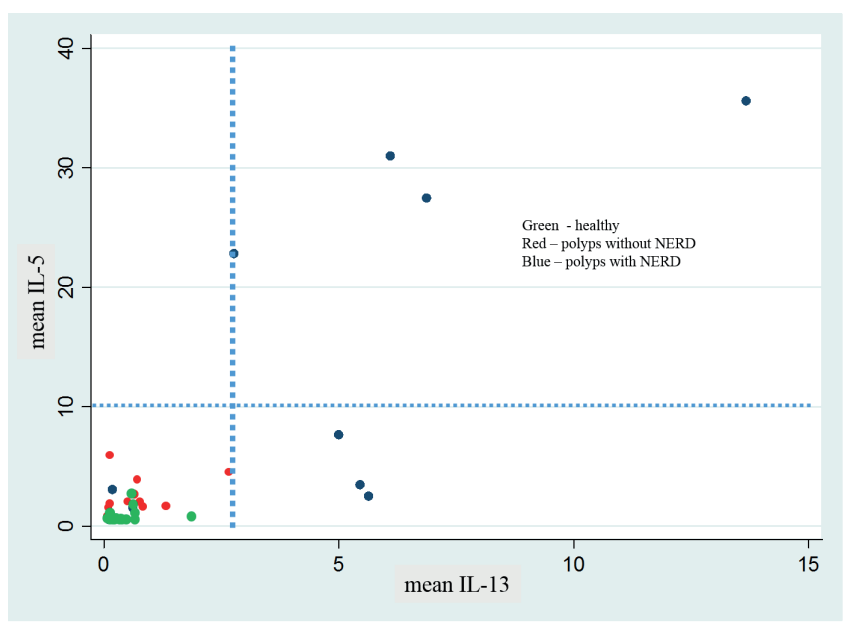

Figure 1. Distribution of subjects within 4 clusters of IL-13 and IL-5. Healthy subjects and all those with absence of NERD are grouped in the lower left quadrant. Most subjects with NERD had IL-13 values $\geq 2.7 \mathrm{pg}$ / $\mathrm{ml}$.

secretions can be an easily accessible parameter for endotyping this disease. Non-invasive mucus investigations have been done before and cytokine levels in sinus secretions seem to correlate with levels in sinus tissue ${ }^{(19)}$. There is evidence that the best collection technique for obtaining nasal secretions is passive absorption via capillary action ${ }^{(20,21)}$.

In line with the current literature we could demonstrate that compared to healthy controls, CRSwNP-patients showed significantly increased amounts of the cytokines IL-6 and IL-5. In peripheral circulation, IL-6 can be released by monocytes, eosinophils, T-cells and B-cells. In the tissue of the respiratory tract it can also be produced by epithelial cells, interstitial fibroblasts and macrophages ${ }^{(22,23)}$. IL-5 is a key mediator in eosinophilic inflammation and is associated with increased intensity of nasal polyposis and asthma ${ }^{(4,24,25)}$. CRSwNP in Western white patients most often represent a Th2 dominated inflammation with increased IL-5 and IL-13. The higher the values of these Th2-cytokines, the more severe is the clinical course ${ }^{(5,8,26)}$. NERD patients in our study represent a more intense eosinophilic inflammation and suffer from more severe symptoms compared to subjects with CRSwNP without aspirin sensitivity. This corresponds with the current literature ${ }^{(27,28)}$. Baseline values of IL-5 in our NERD patients were significantly higher than in non-NERD patients (Table 2). Tryptase in NERD patients was significantly elevated (Table 2), most probably induced by the impaired PGE2 production which serves as an inhibitor of 5-lipoxygenase, and therefore of mast cell activation. The loss of this inhibition may induce mast cell activation ${ }^{29,30)}$. Interestingly in our NERD population we were able to measure a significantly increased IL-13 compared to subjects with no NSAID induced CRSWNP and to healthy controls (Table 2). IL-13 transmits signals through a shared functional receptor complex (IL-4Ra/IL-13Ra1) and induces asthma 
Table 2. Comparison of nasal cytokine pattern from healthy controls and patients with CRSWNP with and without NSAID intolerance.

\begin{tabular}{|c|c|c|c|c|c|c|c|}
\hline Variable & $\#$ & $\begin{array}{c}\text { Mean values } \\
\mathrm{pg} / \mathrm{ml}\end{array}$ & SD & $\#$ & $\begin{array}{c}\text { Mean values } \\
\mathrm{pg} / \mathrm{ml}\end{array}$ & SD & p-value \\
\hline \multicolumn{8}{|c|}{ Polyps without NERD vs. polyps with NERD } \\
\hline Tryptase & 11 & 11.05 & 17.42 & 10 & 20.81 & 26.56 & 0.327 \\
\hline IL-33 & 13 & 64.57 & 115.82 & 13 & 41.82 & 64.50 & 0.542 \\
\hline IFN- $\gamma$ & 13 & 1.07 & 1.57 & 13 & 1.45 & 3.38 & 0.712 \\
\hline IL-4 & 13 & 6.59 & 13.32 & 13 & 1.60 & 1.40 & 0.192 \\
\hline IL-5 & 13 & 1.52 & 1.52 & 13 & 28.17 & 39.32 & 0.022 \\
\hline IL-6 & 13 & 76.27 & 120.01 & 13 & 102.98 & 63.49 & 0.485 \\
\hline IL-8 & 13 & 396.27 & 180.75 & 13 & 576.54 & 261.64 & 0.052 \\
\hline IL-12p70 & 13 & 0.36 & 0.25 & 13 & 0.39 & 0.19 & 0.739 \\
\hline IL-13 & 13 & 0.57 & 0.74 & 13 & 15.02 & 21.45 & 0.023 \\
\hline IL-17a & 13 & 1.23 & 0.94 & 13 & 1.10 & 0.89 & 0.722 \\
\hline IL-23 & 13 & 65.50 & 78.86 & 13 & 49.88 & 37.91 & 0.526 \\
\hline TNF-a & 13 & 19.44 & 49.74 & 13 & 36.84 & 79.36 & 0.509 \\
\hline \multicolumn{8}{|c|}{ healthy vs. polyps without NERD } \\
\hline Tryptase & 15 & 2.98 & 6.22 & 11 & 11.05 & 17.42 & 0.109 \\
\hline IL-33 & 15 & 36.47 & 27.53 & 13 & 64.57 & 115.82 & 0.370 \\
\hline IFN- $\gamma$ & 15 & 0.64 & 1.28 & 13 & 1.07 & 1.57 & 0.428 \\
\hline IL-4 & 15 & 1.90 & 2.21 & 13 & 6.59 & 13.32 & 0.189 \\
\hline IL-5 & 15 & 0.31 & 0.57 & 13 & 1.52 & 1.52 & 0.008 \\
\hline IL-6 & 15 & 8.83 & 13.29 & 13 & 76.27 & 120.01 & 0.040 \\
\hline IL-8 & 15 & 415.46 & 287.07 & 13 & 396.27 & 180.75 & 0.837 \\
\hline IL-12p70 & 15 & 0.39 & 0.31 & 13 & 0.36 & 0.25 & 0.814 \\
\hline IL-13 & 15 & 0.40 & 0.42 & 13 & 0.57 & 0.74 & 0.460 \\
\hline IL-17a & 15 & 8.07 & 28.01 & 13 & 1.23 & 0.94 & 0.388 \\
\hline IL-23 & 15 & 72.62 & 80.29 & 13 & 65.50 & 78.86 & 0.816 \\
\hline TNF-a & 15 & 3.02 & 6.93 & 13 & 19.44 & 49.74 & 0.216 \\
\hline \multicolumn{8}{|c|}{ healthy vs. polyps with NERD } \\
\hline Tryptase & 15 & 2.98 & 6.22 & 10 & 20.81 & 26.56 & 0.019 \\
\hline IL-33 & 15 & 36.47 & 27.53 & 13 & 41.82 & 64.50 & 0.772 \\
\hline IFN- $\gamma$ & 15 & 0.64 & 1.28 & 13 & 1.45 & 3.38 & 0.391 \\
\hline IL-4 & 15 & 1.90 & 2.21 & 13 & 1.60 & 1.40 & 0.686 \\
\hline IL-5 & 15 & 0.31 & 0.57 & 13 & 28.17 & 39.32 & 0.011 \\
\hline IL-6 & 15 & 8.83 & 13.29 & 13 & 102.98 & 63.49 & $<0.001$ \\
\hline IL-8 & 15 & 415.46 & 287.07 & 13 & 576.54 & 261.64 & 0.135 \\
\hline IL-12p70 & 15 & 0.39 & 0.31 & 13 & 0.39 & 0.19 & 0.969 \\
\hline IL-13 & 15 & 0.40 & 0.42 & 13 & 15.02 & 21.45 & 0.014 \\
\hline IL-17a & 15 & 8.07 & 28.01 & 13 & 1.10 & 0.89 & 0.379 \\
\hline IL-23 & 15 & 72.62 & 80.29 & 13 & 49.88 & 37.91 & 0.359 \\
\hline TNF-a & 15 & 3.02 & 6.93 & 13 & 36.84 & 79.36 & 0.111 \\
\hline
\end{tabular}

symptoms by mucus production, smooth muscle alterations and sub-epithelial fibrosis on the airway mucosa independently from IL-4 function ${ }^{(31-33)}$.

Compared to other studies, in NERD patients this characteristic
Th2 response with increased IL-5 and IL-13 was only partially detected ${ }^{(4,5,8,27,34,35)}$. We suspect that this heterogeneity of inflammatory endotypes in NERD patients is attributable to the variety of clinical manifestations ${ }^{(36)}$ and differences between assays and 
variability in approaches for mucus collection and processing. In CRSwNP refractory to topical GCS, biologicals against IL-5 (mepolizumab) and to the IL-4Ra subunit which inhibits signaling of IL-4 and IL-13 (dupilumab), have expanded the therapeutic possibilities ${ }^{(37-42)}$. Interestingly dupilumab particularly improved CRSwNP and asthma in the difficult-to-treat subgroup of patient with NERD ${ }^{(43)}$. These findings let us assume, that dependent on their concentration, IL-5 and IL-13 are main drivers of NERD and are therefore a potential therapeutic target. In our study at a cut off value of $2.7 \mathrm{pg} / \mathrm{ml}$, IL-13 allowed differentiating between CRSwNP with vs. without NERD accurately. While this cut-off value requires confirmation in future studies, the study showed that the IL-13 parameter discriminates well between the two groups of CRSwNP.

Although the selected cohort is small, we consider the significant results as valid. A downside of the study is that no provocation tests with NSAID has been performed in diagnosing NERD. However according a recent position paper NERD can be considered in patients with a clear history of suffering from asthma and chronic rhinosinusitis whose symptoms exacerbate after ingestion of aspirin and other COX-1 inhibitors ${ }^{(44)}$.

\section{Conclusion}

In our study, we demonstrated that IL-13 is a specific biomarker for patients with NERD, which allows us to differentiate between CRSwNP with vs. without NERD. We therefore suggest that noninvasive cytokine measurement of nasal secretion is a valuable diagnostic assay for endotyping CRSwNP. The characterization of inflammatory endotypes in CRSWNP enables the introduction of the best available therapy in the context of precision medicine $(45,46)$.

\section{List of abbreviations:}

CRS: Chronic rhinosinusitis, CRSsNP: chronic rhinosinusitis without nasal polyps; CRSwNP: Chronic rhinosinusitis with nasal polyposis; CXCL: C-X-C Motif Chemokine Ligand, ECP: eosinophilic cationic protein; GCS: Glucocorticosteroids; IL: interleukin; ILCs: innate lymphoid cells; NSAID: non-steroidal anti-inflammatory drugs NERD: NSAID exacerbated respiratory disease; Th: T helper.

\section{Acknowledgements}

We thank all patients for their participation and Catherine Crowley-Kühn for reading and editing the manuscript. We acknowledge the support of the project financing fund, Department of Immunology, University Hospital Zurich.

\section{Authorship contribution}

MS, SB, IS, JS, SB, US, KI performed data acquisition and analysis; SB, MS, US analyzed clinical data; AV, LMB, US analyzed cytokine measurements; LMB performed statistical analysis; US and MS designed the research and were the principal writers of the manuscript. All authors reviewed the manuscript and contributed in writing.

\section{Conflict of interest}

No competing interests.

\section{References}

1. Hastan D, Fokkens WJ, Bachert C, Newson RB, Bislimovska J, Bockelbrink A, et al. Chronic rhinosinusitis in Europe--an underestimated disease. A GA(2)LEN study. Allergy. 2011;66(9):1216-23.

2. Fokkens WJ, Lund VJ, Mullol J, Bachert C, Alobid I, Baroody F, et al. European Position Paper on Rhinosinusitis and Nasal Polyps 2012. Rhinology Supplement. 2012;23:3 p preceding table of contents, 1-298.

3. Hirsch AG, Stewart WF, Sundaresan AS, Young AJ, Kennedy TL, Scott Greene J, et al. Nasal and sinus symptoms and chronic rhinosinusitis in a population-based sample. Allergy. 2017;72(2):274-81

4. Tomassen P, Vandeplas G, Van Zele T, Cardel LO, Arebro J, Olze H, et al. Inflammatory endotypes of chronic rhinosinusitis based on cluster analysis of biomarkers. J Allergy Clin Immunol. 2016;137(5):1449-56.e4.

5. Turner JH, Chandra RK, Li P, Bonnet K, Schlundt DG. Identification of clinically relevant chronic rhinosinusitis endotypes using cluster analysis of mucus cytokines. J Allergy Clin Immunol. 2018;141(5):1895-7. e7.

6. Hauser LJ, Chandra RK, Li P, Turner JH.
Role of tissue eosinophils in chronic rhinosinusitis-associated olfactory loss. International forum of allergy \& rhinology. 2017;7(10):957-62

7. Van Zele T, Holtappels G, Gevaert P, Bachert C. Differences in initial immunoprofiles between recurrent and nonrecurrent chronic rhinosinusitis with nasal polyps. Am J Rhinol Allergy. 2014;28(3):192-8.

8. Turner JH, Li P, Chandra RK. Mucus T helper 2 biomarkers predict chronic rhinosinusitis disease severity and prior surgical intervention. Int Forum Allergy Rhinol. 2018;8(10):1175-83.

9. Rajan JP, Wineinger NE, Stevenson DD, White AA. Prevalence of aspirin-exacerbated respiratory disease among asthmatic patients: A meta-analysis of the literature. J Allergy Clin Immunol. 2015;135(3):676-81. e1.

10. Stevens WW, Peters AT, Hirsch AG, Nordberg CM, Schwartz BS, Mercer DG, et al. Clinical Characteristics of Patients with Chronic Rhinosinusitis with Nasal Polyps, Asthma, and Aspirin-Exacerbated Respiratory Disease. J Allergy Clin Immunol Pract. 2017;5(4):1061-70.e3.

11. Cahill KN, Boyce JA. Aspirin-exacerbated respiratory disease: Mediators and mechanisms of a clinical disease. J Allergy Clin Immunol. 2017:139(3):764-6.

12. Marquette $\mathrm{CH}$, Saulnier $\mathrm{F}$, Leroy $\mathrm{O}$, Wallaert B, Chopin C, Demarca JM, et al. Long-term prognosis of near-fatal asthma. A 6-year follow-up study of 145 asthmatic patients who underwent mechanical ventilation for a near-fatal attack of asthma. Am Rev Resp Dis. 1992;146(1):76-81.

13. [The Helsinki Declaration of the World Medical Association (WMA). Ethical principles of medical research involving human subjects]. Polski merkuriusz lekarski : organ Polskiego Towarzystwa Lekarskiego. 2014:36(215):298-301.

14. Akdis M, Aab A, Altunbulakli C, Azkur K, Costa RA, Crameri R, et al. Interleukins (from IL-1 to IL-38), interferons, transforming growth factor $\beta$, and TNF-a: Receptors, functions, and roles in diseases. J Allergy Clin Immunol. 2016;138(4):984-1010.

15. Sedger LM, McDermott MF. TNF and TNFreceptors: From mediators of cell death and inflammation to therapeutic giants - past, present and future. Cytokine Growth factor Rev. 2014;25(4):453-72.

16. Russo RC, Garcia CC, Teixeira MM, Amaral FA 
The CXCL8/IL-8 chemokine family and its receptors in inflammatory diseases. Expert Rev Clin Immunol. 2014;10(5):593-619.

17. Bachert C, Zhang N, Hellings PW, Bousquet J. Endotype-driven care pathways in patients with chronic rhinosinusitis. Allergy Clin Immunol. 2018;141(5):1543-51.

18. Soyka MB, Wawrzyniak P, Eiwegger T, Holzmann D, Treis A, Wanke $K$, et al. Defective epithelial barrier in chronic rhinosinusitis: the regulation of tight junctions by IFN- $\gamma$ and IL-4. J Allergy Clin Immunol. 2012;130(5):1087-96.e10.

19. Oyer SL, Mulligan JK, Psaltis AJ, Henriquez OA, Schlosser RJ. Cytokine correlation between sinus tissue and nasal secretions among chronic rhinosinusitis and controls. Laryngoscope. 2013;123(12):E72-8.

20. Klimek L, Rasp G. Norm values for eosinophil cationic protein in nasal secretions: influence of specimen collection. Clin Exp Allergy. 1999;29(3):367-74.

21. Riechelmann H, Deutschle T, Rozsasi A, Keck T, Polzehl D, Burner H. Nasal biomarker profiles in acute and chronic rhinosinusitis. Clin Exp Allergy. 2005;35(9):1186-91.

22. Peters AT, Kato A, Zhang N, Conley DB, Suh L, Tancowny B, et al. Evidence for altered activity of the IL-6 pathway in chronic rhinosinusitis with nasal polyps. J Allergy Clin Immunol. 2010;125(2):397-403.e10.

23. Rincon M, Irvin CG. Role of IL-6 in asthma and other inflammatory pulmonary diseases. Int J Biol Sci. 2012;8(9):1281-90.

24. Bachert C, Wagenmann M, Hauser $U$, Rudack C. IL-5 synthesis is upregulated in human nasal polyp tissue. J Allergy Clin Immunol. 1997:99(6 Pt 1):837-42.

25. Mortuaire G, Leroy X, Gengler I, Chevalier $D$, Prin L, Picry A. Histopathological classification of refractory chronic rhinosinusitis with nasal polyps. Histol Histopathol. 2015;30(12):1447-54

26. Van Zele T, Claeys S, Gevaert P, Van Maele G, Holtappels G, Van Cauwenberge P, et al. Differentiation of chronic sinus diseases by measurement of inflammatory mediators. Allergy. 2006;61(11):1280-9.

27. Stevens WW, Ocampo CJ, Berdnikovs $S$ Sakashita M, Mahdavinia M, Suh L, et al. Cytokines in Chronic Rhinosinusitis. Role in Eosinophilia and Aspirin-exacerbated Respiratory Disease. Am J Respir Crit Care Med. 2015:192(6):682-94

28. Smith KA, Orlandi RR, Oakley G, Meeks H,
Curtin K, Alt JA. Long-term revision rates for endoscopic sinus surgery. Int Forum Allergy Rhinol. 2019;9(4):402-8.

29. Kay LJ, Yeo WW, Peachell PT. Prostaglandin E2 activates EP2 receptors to inhibit human lung mast cell degranulation. $\mathrm{Br} \mathrm{J}$ Pharmacol. 2006;147(7):707-13.

30. Cahill KN, Murphy K, Singer J, Israel E, Boyce JA, Laidlaw TM. Plasma tryptase elevation during aspirin-induced reactions in aspirinexacerbated respiratory disease. J Allergy Clin Immunol. 2019;143(2):799-803.e2.

31. Wills-Karp M, Luyimbazi J, Xu X, Schofield B, Neben TY, Karp CL, et al. Interleukin-13: central mediator of allergic asthma. Science (New York, NY). 1998;282(5397):2258-61.

32. Wynn TA. IL-13 effector functions. Ann Rev Immunol. 2003:21:425-56.

33. Bhattacharjee A, Shukla M, Yakubenko VP, Mulya A, Kundu S, Cathcart MK. IL-4 and IL-13 employ discrete signaling pathways for target gene expression in alternatively activated monocytes/macrophages. Free Radic Biol Med. 2013;54:1-16.

34. Olze H, Förster U, Zuberbier T, Morawietz L, Luger EO. Eosinophilic nasal polyps are a rich source of eotaxin, eotaxin-2 and eotaxin-3. Rhinology. 2006;44(2):145-50

35. Pérez-Novo CA, Watelet JB, Claeys C, Van Cauwenberge $\mathrm{P}$, Bachert $C$. Prostaglandin leukotriene, and lipoxin balance in chronic rhinosinusitis with and without nasal polyposis. J Allergy Clin Immunol. 2005;115(6):1189-96.

36. Bochenek G, Kuschill-Dziurda J, Szafraniec K, Plutecka H, Szczeklik A, NizankowskaMogilnicka E. Certain subphenotypes of aspirin-exacerbated respiratory disease distinguished by latent class analysis. J Allergy Clin Immunol. 2014;133(1):98-103.e1-6.

37. Gevaert $P$, Van Bruaene N, Cattaert T, Van Steen $K$, Van Zele $T$, Acke $F$, et al. Mepolizumab, a humanized anti-IL-5 $\mathrm{mAb}$, as a treatment option for severe nasal polyposis. J Allergy Clin Immunol. 2011;128(5):989-95.e1-8.

38. Bachert C, Sousa AR, Lund VJ, Scadding GK, Gevaert P, Nasser S, et al. Reduced need for surgery in severe nasal polyposis with mepolizumab: Randomized trial. J Allergy Clin Immunol. 2017;140(4):1024-31.e14.

39. Wenzel S, Ford L, Pearlman D, Spector $S$, Sher L, Skobieranda F, et al. Dupilumab in persistent asthma with elevated eosinophil levels. New Eng J Med. 2013;368(26):2455-
66.

40. Bachert C, Mannent L, Naclerio RM, Mullo J, Ferguson BJ, Gevaert P, et al. Effect of Subcutaneous Dupilumab on Nasal Polyp Burden in Patients With Chronic Sinusitis and Nasal Polyposis: A Randomized Clinical Trial. Jama. 2016;315(5):469-79.

41. Jonstam K, Swanson BN, Mannent LP, Cardell LO, Tian N, Wang Y, et al. Dupilumab reduces local type 2 pro-inflammatory biomarkers in chronic rhinosinusitis with nasal polyposis. Allergy. 2019;74(4):743-52.

42. Bachert C, Han JK, Desrosiers M, Hellings PW, Amin N, Lee SE, et al. Efficacy and safety of dupilumab in patients with severe chronic rhinosinusitis with nasal polyps (LIBERTY NP SINUS-24 and LIBERTY NP SINUS-52): results from two multicentre, randomised, double-blind, placebo-controlled, parallel-group phase 3 trials. Lancet. 2019;394(10209):1638-50

43. Laidlaw TM, Mullol J, Fan C, Zhang D, Amin N, Khan A, et al. Dupilumab improves nasal polyp burden and asthma control in patients with CRSwNP and AERD. J Allergy Clin Immunol Pract. 2019;7(7):2462-5.e1.

44. Kowalski ML, Agache I, Bavbek S, Bakirtas A, Blanca M, Bochenek G, et al. Diagnosis and management of NSAID-Exacerbated Respiratory Disease (N-ERD)-a EAACI position paper. Allergy. 2019;74(1):28-39.

45. Collins FS, Varmus $H$. A new initiative on precision medicine. New Eng J Med. 2015;372(9):793-5.

46. De Greve G, Hellings PW, Fokkens WJ, Pugin B, Steelant B, Seys SF. Endotype-driven treatment in chronic upper airway diseases. Clin Transl Allergy. 2017;7:22

Urs C. Steiner

Department of Immunology

University Hospital Zurich

Gloriastrasse 23

CH-8091 Zurich Switzerland

Tel: +41442551112

E-mail: urs.steiner@usz.ch 